(6) OPEN ACCESS

Correspondence to Dr Tianrong Cheng, Office of Science, Center for Tobacco Products, Food and Drug Administration, 9200 Corporate Blvd, Rockville, MD 20850, USA;

Tianrong.Cheng@fda.hhs.gov

Received 4 December 2013 Revised 27 February 2014 Accepted 28 February 2014

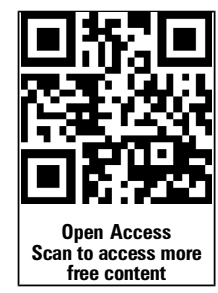

To cite: Cheng T. Tob Control 2014;23:ii11-ii17.

\title{
Chemical evaluation of electronic cigarettes
}

\author{
Tianrong Cheng
}

\begin{abstract}
Objective To review the available evidence evaluating the chemicals in refill solutions, cartridges, aerosols and environmental emissions of electronic cigarettes (e-cigarettes).
\end{abstract}

Methods Systematic literature searches were conducted to identify research related to e-cigarettes and chemistry using 5 reference databases and 11 search terms. The search date range was January 2007 to September 2013. The search yielded 36 articles, of which 29 were deemed relevant for analysis.

Results The levels of nicotine, tobacco-specific nitrosamines (TSNAs), aldehydes, metals, volatile organic compounds (VOCs), flavours, solvent carriers and tobacco alkaloids in e-cigarette refill solutions, cartridges, aerosols and environmental emissions vary considerably. The delivery of nicotine and the release of TSNAs, aldehydes and metals are not consistent across products. Furthermore, the nicotine level listed on the labels of e-cigarette cartridges and refill solutions is often significantly different from measured values. Phenolic compounds, polycyclic aromatic hydrocarbons and drugs have also been reported in e-cigarette refill solutions, cartridges and aerosols. Varying results in particle size distributions of particular matter emissions from e-cigarettes across studies have been observed. Methods applied for the generation and chemical analyses of aerosols differ across studies. Performance characteristics of e-cigarette devices also vary across and within brands.

Conclusions Additional studies based on knowledge of e-cigarette user behaviours and scientifically validated aerosol generation and chemical analysis methods would be helpful in generating reliable measures of chemical quantities. This would allow comparisons of e-cigarette aerosol and traditional smoke constituent levels and would inform an evaluation of the toxicity potential of e-cigarettes.

\section{INTRODUCTION}

e-cigarettes are nicotine delivery devices designed to look and feel like a traditional cigarette, a pen or a fashion accessory. They are often marketed as tobacco-free nicotine delivery devices. ${ }^{1}$ In a typical device configuration, instead of burning tobacco, a user draws air through the device; an airflow sensor or a physical power button activates a battery that powers an atomizer to produce an aerosol from liquid containing nicotine and flavourings. A high percentage of the liquid is composed of carrier solvents, such as glycerol and/or propylene glycol. Aerosol generated from an e-cigarette is commonly but inaccurately referred to as 'vapour.' Vapour refers to the gaseous state of a substance; in contrast, an aerosol is a suspension of fine particles of liquid, solid or both in a gas. Both the particulate and gas phases are mixtures of chemical substances in e-cigarette aerosols. The e-cigarette aerosol simulates cigarette smoke. ${ }^{2}$ Following a puff, the aerosol is delivered into the user's mouth and lungs by inhalation, after which the remaining aerosol is exhaled into the environment. ${ }^{1}$ These products are commercialised in various forms (or 'models') with different design characteristics and generate different physical and chemical characteristics during operation.

e-cigarettes are becoming increasingly popular, a concerning trend given limited information about their chemistry. Marketers of e-cigarettes have made a variety of claims indicating that e-cigarettes are safer than conventional cigarettes and that their use facilitates smoking cessation. ${ }^{3}$ However, e-cigarette manufacturers do not provide complete information on the chemicals used in the manufacturing process or the chemicals that may be released or synthesised during the aerosol generation process that occurs during use. Minimal valid chemistry data are available on e-cigarette emissions. Furthermore, nicotine levels are intentionally formulated to create target strengths, yet measured levels may not match the label claim. ${ }^{4}$ Consequently, safety concerns exist regarding e-cigarette user exposure to harmful and potentially harmful constituents (HPHCs), including nicotine, which has the potential to cause addiction and other adverse events. ${ }^{5}$ This paper summarises existing research findings related to e-cigarette chemical composition; it also highlights limitations and information gaps that are critical for reliable chemistry data collection necessary for e-cigarette hazard evaluation.

\section{METHODS}

Systematic literature searches were conducted through September 2013 to identify research related to e-cigarettes and chemistry. Five reference databases (Web of Knowledge, PubMed, SciFinder, Embase and EBSCOhost) were searched using a set of relevant search terms used singly or in combination. Search terms included the following: 'electronic nicotine devices' OR 'electronic nicotine device' OR 'electronic nicotine delivery systems' OR 'electronic nicotine delivery system' OR 'electronic cigarettes' OR 'electronic cigarette' OR 'e-cigarettes' OR 'e-cigarette' OR 'e-cig' OR 'e-cigs' AND 'chemistry.' The search date range was restricted between January 2007, when the first study of chemicals in e-cigarettes was published, and September 2013.

To be considered for inclusion, the article had to (1) be written in English, (2) be publicly available, (3) be published in a peer-reviewed journal and (4) deal partly or exclusively with chemistry. Excluded sources included (1) indirect data sources, (2) patents and (3) conference presentations. 
Table 1 Nicotine reported in refill solutions, cartridges, aerosols and environmental emission of e-cigarette products

\begin{tabular}{|c|c|c|c|c|}
\hline Literature & Matrix & Units & Nicotine level & Deviation from label $^{*}$ \\
\hline Goniewicz et al $/^{4}$ & $\begin{array}{l}\text { Refill solution } \\
\text { Cartridge } \\
\text { Aerosol }\end{array}$ & $\begin{array}{l}\mathrm{mg} \\
\mathrm{mg} \\
\mathrm{mg} / 150 \text { puffs }\end{array}$ & $\begin{array}{l}0 \pm 0.0 \text { to } 25 \pm 1.1 \\
0 \pm 0.0 \text { to } 19 \pm 0.5 \\
0.3 \pm 0.2 \text { to } 8.7 \pm 1.0\end{array}$ & $\begin{array}{l}-75 \text { to } 28 \% \\
-89 \text { to } 25 \% \\
\text { N.A. }\end{array}$ \\
\hline Etter et $a l^{13}$ & Refill solution & $\mathrm{mg} / \mathrm{mL}$ & N.D. to 29.0 & -15 to $21 \% \dagger$ \\
\hline Kirschner et $a l^{16}$ & Refill solution & $\mathrm{mg} / \mathrm{mL}$ & $14.8 \pm 0.2$ to $87.2 \pm 2.7$ & -50 to $40 \% \dagger$ \\
\hline Cameron et $a l^{15}$ & Refill solution & $\mathrm{mg} / \mathrm{mL}$ & $8.5 \pm 0.16$ to $22.2 \pm 0.62$ & -66 to $42 \% \dagger$ \\
\hline Pellegrino et a ${ }^{6}$ & $\begin{array}{l}\text { Cartridge } \\
\text { Aerosol }\end{array}$ & $\begin{array}{l}\% \mathrm{~W} / \mathrm{W} \\
\mathrm{mg} / \mathrm{m}^{3}\end{array}$ & $\begin{array}{l}<0.001 \text { to } 0.25 \\
<0.01 \text { to } 6.21\end{array}$ & $\begin{array}{l}\text { N.A. } \\
\text { N.A. }\end{array}$ \\
\hline McAuley et $a l^{11}$ & Indoor air & $\mathrm{ng} / \mathrm{L}$ & 538 to 8770 & N.A. \\
\hline Cheah et $a l^{17}$ & Cartridge & mg/cartridge & 0.00 to 15.3 & -89 to $105 \% \dagger$ \\
\hline Trehy et $a l^{7}$ & $\begin{array}{l}\text { Refill solutions } \\
\text { Cartridge } \\
\text { Aerosol }\end{array}$ & $\begin{array}{l}\mathrm{mg} / \mathrm{mL} \\
\mathrm{mg} / \mathrm{cartridge} \\
\mu \mathrm{g} / 100 \mathrm{~mL} \text { puff }\end{array}$ & $\begin{array}{l}0 \text { to } 25.6 \\
0 \text { to } 21.8 \\
0 \text { to } 43.2\end{array}$ & $\begin{array}{l}-100 \text { to } 100 \% \dagger \\
-100 \text { to } 100 \% \dagger \\
\text { N.A. }\end{array}$ \\
\hline Cobb et $a l^{8}$ & $\begin{array}{l}\text { Cartridge } \\
\text { Aerosol }\end{array}$ & $\begin{array}{l}\text { mg/cartridge } \\
\mu \mathrm{g} / 35 \mathrm{~mL} \text { puff }\end{array}$ & $\begin{array}{l}3.23 \pm 0.5 \text { to } 4.07 \pm 0.54 \\
0.3 \text { for puffs } 11 \text { to } 50 \\
\text { to } 1.0 \text { for puffs } 1 \text { to } 10\end{array}$ & $\begin{array}{l}-80 \text { to }-77 \% \dagger \\
\text { N.A. }\end{array}$ \\
\hline Westenberger $^{9}$ & $\begin{array}{l}\text { Cartridge } \\
\text { Aerosol }\end{array}$ & $\begin{array}{l}\mathrm{mg} / \text { cartridge } \\
\mu \mathrm{g} / 100 \mathrm{~mL} \text { puff }\end{array}$ & $\begin{array}{l}0.00 \text { to } 6.76 \\
0.35 \text { to } 43.2\end{array}$ & $\begin{array}{l}\text { N.A. } \\
\text { N.A. }\end{array}$ \\
\hline Westenberger $^{10}$ & Refill solution & $\mu \mathrm{g} / \mathrm{mL}$ & N.D. to 25.6 & N.A. \\
\hline
\end{tabular}

*Deviation from label=(measured value - labelled value) * $100 /$ labelled value

tCalculation performed by this analysis based on reported data in each study.

N.A., not available; N.D., not detected.

The search yielded a total of 261 articles that met the inclusion criteria. Exclusion criteria reduced the number of articles to 158 . The titles and abstracts (when titles provided insufficient detail) of these 158 articles were screened for relevance. This screening identified 36 articles for full-text review, including a manual search of the reference lists of selected articles to identify additional relevant publications.

Following the full-text review, 29 articles were deemed relevant for this analysis. The validity and strength of each study were determined based on a qualitative assessment of study scope objectives and research design. Meaningful study limitations are noted in the analysis.

\section{RESULTS}

Chemical substances reported in studies of e-cigarette refill solutions, cartridges, aerosols and environmental emissions are provided in tables 1-7. The instrumental methods developed by each study for specific categories of chemicals are provided in tables 8 and 9. Methods, conditions and parameters for machine (laboratory device) aerosol generation reported in these studies are provided in tables 10 and 11 . The combined results of these research studies are described below.

\section{Nicotine}

Table 1 summarises the current research regarding the nicotine levels found in e-cigarette cartridges, refill solutions, aerosols and environmental emissions. Nicotine is the primary addictive substance in tobacco products. The data indicate that the nicotine levels in e-cigarettes vary considerably. e-cigarette brands and models differ in the efficacy and consistency of nicotine yields, and the delivery of nicotine is not uniform either from puff-to-puff or across products of the same brand. ${ }^{4}$ 6-11 Furthermore, the level of nicotine listed on the labels of e-cigarette cartridges and refill solutions is often significantly different

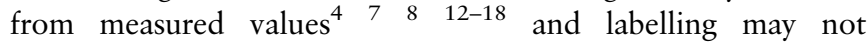
adequately convey the amount or concentration of nicotine. ${ }^{19}$ For example, Goniewicz et al conducted a quantitative analysis of nicotine in aerosols generated from 15 e-cigarette brands (16 products) that were selected based on their market popularity. They found that total nicotine in aerosol varied by brand from 0.5 to $15.4 \mathrm{mg}$ per 300 puffs $(20$ series of 15 puffs, $70 \mathrm{~mL} /$ puff, triplicate tests of each product) and that the nicotine in aerosol varied from $21 \%$ to $85 \%$ of the nicotine present in the cartridge. Westenberger repeatedly tested three individual cartridges with the same label and obtained results varying from 26.8 to $43.2 \mu \mathrm{g}$ nicotine per $100 \mathrm{~mL}$ puff (estimated to be $8.04-$ $13.0 \mathrm{mg}$ nicotine per 300 puffs). Consequently, environmental nicotine emissions from e-cigarettes differ across brands. For example, McAuley studied nicotine emissions from aerosols of four different high-nicotine content e-liquids in cartridges and found $538-8770 \mathrm{ng} / \mathrm{L}$ of nicotine in indoor air compared with 5039 to $48050 \mathrm{ng} / \mathrm{L}$ from conventional cigarette smoke. ${ }^{11}$

Table 2 Aldehydes reported in refill solutions and aerosols of e-cigarettes

\begin{tabular}{|c|c|c|c|c|c|c|c|}
\hline Literature & Matrix & Units & Formaldehyde & Acetaldehyde & Acrolein & $o$-Methyl benzaldehyde & Acetone \\
\hline Goniewicz et al ${ }^{20}$ & Aerosol & $\mu \mathrm{g} / 150$ puffs & $\begin{array}{l}3.2 \pm 0.8 \text { to } \\
56.1 \pm 1.4\end{array}$ & $\begin{array}{l}2.0 \pm 0.1 \text { to } \\
13.6 \pm 2.1\end{array}$ & $\begin{array}{l}\text { N.D. to } \\
41.9 \pm 3.4\end{array}$ & $\begin{array}{l}1.3 \pm 0.8 \text { to } \\
7.1 \pm 0.4\end{array}$ & N.T. \\
\hline Lim and Shin 25 & Refill solution & $\mathrm{mg} / \mathrm{L}$ & 0.02 to 10.09 & 0.10 to 15.63 & N.D. & N.T. & N.T. \\
\hline Ohta et $a^{23}$ & Aerosol & $\mathrm{mg} / \mathrm{m}^{3}$ & 260 & $<\mathrm{LOQ}$ & $<\mathrm{LOQ}$ & N.T. & N.T. \\
\hline Uchiyama et $a l^{24}$ & Aerosol & $\mathrm{mg} / \mathrm{m}^{3}$ & 8.3 & 11 & 9.3 & N.T. & 2.9 \\
\hline Laugesen ${ }^{22}$ & Aerosol & $\mathrm{ppm} / 38 \mathrm{~mL}$ puff & 0.25 & 0.34 & N.D. to 0.33 & N.T. & 0.16 \\
\hline
\end{tabular}

$<\mathrm{LOQ}$, below the limit of quantitation but above the limit of detection; N.D., not detected; N.T., not tested by the study. 
Table 3 Tobacco-specific nitrosamines reported in aerosols, refill solutions and cartridges of e-cigarettes

\begin{tabular}{|c|c|c|c|c|c|c|}
\hline Literature & Matrix & Units & NNN & NNK & NAT & NAB \\
\hline Goniewicz et al ${ }^{20}$ & Aerosol & $\mu \mathrm{g} / 150$ puffs & N.D. to $4.3 \pm 2.4$ & N.D. to $28.3 \pm 13.2$ & N.T. & N.T. \\
\hline Kim and Shin ${ }^{21}$ & Refill solution & $\mu \mathrm{g} / \mathrm{L}$ & 0.34 to 60.08 & 0.22 to 9.84 & 0.09 to 62.19 & 0.11 to 11.11 \\
\hline Westenberger et a $l^{9}$ & Cartridge & mg/cartridge & N.D. to $<\mathrm{LOQ}$ & N.D. to $<\mathrm{LOQ}$ & N.D. to $<\mathrm{LOQ}$ & N.D. to $<\mathrm{LOQ}$ \\
\hline Laugesen ${ }^{22}$ & Cartridge & ng/cartridge & BDL to 3.87 & 0.26 to 1.46 & BDL to 2.16 & N.Q. to 0.69 \\
\hline
\end{tabular}

$<\mathrm{LOQ}$, below the limit of quantitation but above the limit of detection; BDL, below detection limit; N.D., not detected; N.Q., not quantifiable; N.T., not tested by the study.

NNN, N-nitrosonornicotine; NNK, 4-(N-nitrosomethylamino)-1-(3-pyridyl)-1-butanone; NAT, N-nitrosoanatabine; NAB, N-nitrosoanabasine.

Given these issues with nicotine content variability, all studies recommend that e-cigarette manufacturers implement quality standards regarding nicotine content.

\section{Other chemical substances}

Quantitative and qualitative studies have identified a wide variety of chemical components in the cartridges, refill solutions and aerosols of e-cigarettes. Tables 2-7 summarise the chemical substances that have been detected and/or quantified in e-cigarette refill solutions, cartridges and aerosols. Substances identified include tobacco-specific nitrosamines (TSNAs), ${ }^{9}$ 20-22 aldehydes, ${ }^{20} 22-25$ metals, ${ }^{20} 2226$ volatile organic compounds (VOCs), ${ }^{6} 202227$ phenolic compounds, ${ }^{22}$ polycyclic aromatic hydrocarbons (PAHs), ${ }^{22} 28$ flavours, ${ }^{6}{ }^{22}$ solvent carriers, ${ }^{6} 2227$ tobacco alkaloids, ${ }^{7} \quad 10 \quad 13$ and drugs (amino-tadalafil and rimonabant). ${ }^{18}$

These TSNAs, aldehydes, metals, VOCs, phenolic compounds, PAHs and tobacco alkaloids are harmful or potentially harmful constituents released during the smoking of conventional cigarettes, and their public health risks have been the focus of many studies. In contrast, e-cigarettes use solvent carriers, such as propylene glycol and glycerol, as humectants in ecigarette solutions to produce aerosols that simulate conventional cigarette smoke. These humectants are oxidised to form the same aldehydes found in conventional cigarette smoke when a heating voltage greater than $3 \mathrm{~V}$ is used during the aerosol generation process. ${ }^{23} 2526$ The data reported by Goniewicz et al indicate that e-cigarette brands and product models differ in yields of TSNAs, aldehydes, metals and VOCs. ${ }^{20}$ For example, the acrolein level in the aerosol generated from two different product models within the same brand is reported to be $4.4 \pm 2.5 \mu \mathrm{g} / 150$ puffs for one model and $16.6 \pm 2.5 \mu \mathrm{g} / 150$ puffs for the other model. An even greater variance in the acrolein level is observed when comparing products across brands, where an acrolein level was determined to be as large as $41.9 \pm 3.4 \mu \mathrm{g} / 150$ puffs in aerosol of a product from a different brand. The relative standard deviations (SDs) reported for all measurements range from $0 \%$ to $100 \%$ of the mean values, indicating inconsistencies in the release of these chemicals across products. Similarly, in 2013 Etter et al found that e-cigarette sub-brands differ in levels of tobacco alkaloids. ${ }^{13}$ Within a brand, nicotine-N-oxide (one of the tobacco alkaloids) is at $0.16 \%$ (of nicotine content) in a tobacco-flavoured sub-brand, $0.09 \%$ in a menthol-flavoured sub-brand and $0.03 \%$ in an unflavoured sub-brand.

Nevertheless, analytical methods applied in these studies are inconsistent. Tables 8 and 9 summarise the instrumental methods developed for specific categories of target analytes by each study. Analytical methodology for qualitative and/or quantitative determination of a constituent in cigarette smoke generally encompasses two areas of effort: sample preparation and instrumental analysis. Sample preparation involves smoke/ aerosol generation, sample extraction and sample collection. Instrumental analysis involves analysing the sample to identify

Table 4 Metals reported in aerosols and cartridges of e-cigarettes

\begin{tabular}{|c|c|c|c|c|c|c|}
\hline Literature & Units & Cadmium & Nickel & Lead & Chromium & Arsenic \\
\hline Goniewicz et a ${ }^{20}$ & $\mu \mathrm{g} / 150$ puffs & $\begin{array}{l}\text { N.D. to } \\
0.22 \pm 0.16\end{array}$ & $0.11 \pm 0.05$ to $0.29 \pm 0.08$ & $\begin{array}{l}0.03 \pm 0.03 \text { to } \\
0.57 \pm 0.28\end{array}$ & N.T. & N.T. \\
\hline Williams et $a{ }^{26}$ & $\mu \mathrm{g} / 10$ puffs & N.T. & 0.005 & 0.017 & 0.007 & N.T. \\
\hline Laugesen ${ }^{22}$ & $\mu \mathrm{g} /$ cartridge & N.D. & N.D. & N.D. & N.D. & N.D. \\
\hline
\end{tabular}

N.D., not detected; N.T., not tested by the study.

Table 5 Tobacco alkaloids reported in refill solutions, cartridges and aerosols of e-cigarettes

\begin{tabular}{|c|c|c|c|c|c|c|c|c|}
\hline Literature & Matrix & Units & Cotinine & Myosmine & Anatabine & Anabasine & $\beta$-Nicotyrine & Nornicotine \\
\hline Etter et $a l^{13}$ & Refill solution & $\%$ of nicotine & 0.04 to 0.21 & 0.05 to 0.42 & 0.13 to 1.56 & 0.04 to 0.45 & 0.06 & 0.02 to 0.10 \\
\hline Trehy et $a l^{7}$ & $\begin{array}{l}\text { Cartridge } \\
\text { Aerosol }\end{array}$ & $\begin{array}{l}\mathrm{mg} / \text { cartridge } \\
\mathrm{mg} / 30 \times 100 \mathrm{~mL} \text { puffs }\end{array}$ & $\begin{array}{l}\text { N.D. } \\
\text { N.D. }\end{array}$ & $\begin{array}{l}<\mathrm{LOQ} \text { to } 0.08 \\
\text { N.D. }\end{array}$ & $\begin{array}{l}\text { N.D. to } 0.82 \\
\text { N.D. to }<\text { LOQ }\end{array}$ & $\begin{array}{l}\text { N.D. to }<\mathrm{LOQ} \\
\text { N.D. }\end{array}$ & $\begin{array}{l}\text { N.D. to }<\text { LOQ } \\
\text { N.D. }\end{array}$ & $\begin{array}{l}\text { N.T. } \\
\text { N.T. }\end{array}$ \\
\hline Westenberger ${ }^{9}$ & $\begin{array}{l}\text { Cartridge } \\
\text { Aerosol }\end{array}$ & $\begin{array}{l}\text { mg/cartridge } \\
\mu \mathrm{g} / 100 \mathrm{~mL} \text { puff }\end{array}$ & $\begin{array}{l}\text { N.D. to }<\mathrm{LOQ} \\
\text { N.D. to } 0.4\end{array}$ & $\begin{array}{l}\text { N.D. to }<\text { LOQ } \\
\text { N.T. }\end{array}$ & $\begin{array}{l}\text { N.A. } \\
\text { N.T. }\end{array}$ & $\begin{array}{l}\text { N.D. to }<\text { LOQ } \\
\text { N.T. }\end{array}$ & $\begin{array}{l}\text { N.D. to }<\mathrm{LOQ} \\
\text { N.D. to } \mathrm{D} \text {. }\end{array}$ & $\begin{array}{l}\text { N.A. } \\
\text { N.T. }\end{array}$ \\
\hline Westenberger $^{10}$ & Refill solution & $\mu \mathrm{g} / \mathrm{mL}$ & N.D. to 178 & 36 to 71 & 18 to 57 & N.D. & 1 to 6 & N.T. \\
\hline
\end{tabular}

$<\mathrm{LOQ}$, below the limit of quantitation but above the limit of detection; D., detected; N.A., not available; N.D., not detected; N.T., not tested by the study. 
Table 6 Polycyclic aromatic hydrocarbons and cresol reported in aerosols from one e-cigarette cartridge

\begin{tabular}{|c|c|c|c|c|c|c|}
\hline \multirow[b]{2}{*}{ Literature } & \multirow[b]{2}{*}{ Cresol } & \multicolumn{5}{|l|}{ PAHs } \\
\hline & & Anthracene & Phenanthrene & 1-Methyl phenanthrene & Pyrene & Others \\
\hline Laugesen $^{22}$ & 0.16 ppm/38 mL puff & 7 ng/cartridge & 48 ng/cartridge & $5 \mathrm{ng} /$ cartridge & 36 ng/cartridge & N.D. \\
\hline
\end{tabular}

Table 7 Volatile organic compounds reported in aerosols of e-cigarettes

\begin{tabular}{lllllll}
\hline Literature & Units & Toluene & $\mathbf{p}, \mathbf{m}$-Xylene & Propylene Glycol & Glycerin & 3-Methylbutyl-3-methylbutanoate \\
\hline Schripp et $\left.a\right|^{27}$ & $\mu \mathrm{g} / \mathrm{puff}$ & N.A. & N.A. & 1673 to 5525 & 5 to 15 & 0.1 to 1.1 \\
Goniewicz $^{20}$ & $\mu \mathrm{g} / 150$ puffs & N.D. to $6.3 \pm 1.5$ & N.D. to $0.2 \pm 0.1$ & N.T. & N.T. & N.T. \\
Pellegrino et $a l^{6}$ & $\mathrm{mg} / \mathrm{m}^{3}$ & N.T. & N.T. & 1660 & 610 & N.T. \\
Laugesen $^{22}$ & $\mathrm{ppm} / 38 \mathrm{~mL}$ puff & N.T. & 0.18 & 32 & N.T. & N.T. \\
\hline
\end{tabular}

N.A., not available; N.D., not detected; N.T., not tested by the study.

and quantify analytes of interest. The instrument is commonly selected based on the scientific characteristics of the target analyte, the applicable features of the instrument and the instrument accessibility.

Taking instrumental TSNA analysis as an example, ultraperformance liquid chromatography coupled with mass spectrometry (LCMS) was used in Goniewicz's research, ${ }^{20}$ whereas high-performance liquid chromatography coupled with tandem mass spectrometry (LCMSMS) was used in Kim's study. ${ }^{21}$ The two instruments differ in performance characteristics such as detection limit, resolution and linear dynamic range.
By instrumental design, LCMSMS uses two mass spectrometers connected in series, as opposed to one mass spectrometer for LCMS. LCMSMS provides increased sensitivity and resolution when detecting an analyte in a complex sample matrix, such as smoke, by mass filtering and fragmentation pattern recognition of a specific target mass that undergoes inert gas fragmentation in the collision chamber. This also results in LCMSMS having a wider linear dynamic range than LCMS. These advantages of LCMSMS are beneficial to the analysis of a cigarette smoke/aerosol sample because the target analyte levels are frequently near the limit of quantitation for LCMS, and the

Table 8 Instrumental methods developed for nicotine, TSNAs, aldehydes, metals, VOCs and phenols

\begin{tabular}{|c|c|c|c|c|c|c|}
\hline Literature & Nicotine & TSNAs & Aldehydes & Metals & VOCs & Phenols \\
\hline Cameron et $a l^{15}$ & LC/MS/MS & & & & & \\
\hline Etter et $a l^{13}$ & UHPLC/DAD, GC/FID, GC/MS & & & & & \\
\hline Goniewicz et al ${ }^{4}$ & $\mathrm{GC} / \mathrm{TSD}$ & & & & & \\
\hline Goniewicz et al ${ }^{20}$ & & UPLC/MS & HPLC/DAD & ICP/MS & GC/MS & \\
\hline Kim and Shin ${ }^{21}$ & & LC/MS/MS & & & & \\
\hline Kubica et $a l^{14}$ & LC/MS/MS/trap & & & & & \\
\hline Lim and Shin ${ }^{25}$ & & & HS GC/MS & & & \\
\hline Kirschner et $a l^{16}$ & LC/TOF & & & & & \\
\hline Schripp et $a l^{27}$ & & & HPLC/UV & & GC/MS & \\
\hline Uryupin et $a \beta^{30}$ & NMR & & & & & \\
\hline Williams et $a l^{26}$ & & & & ICP/OES & & \\
\hline Cheah et al ${ }^{17}$ & GC/FID, GC/MS & & & & & \\
\hline McAuley et al ${ }^{11}$ & GC/NPD & GC/MS & HPLC/UV & & HS GC/MS & \\
\hline Ohta et $a l^{23}$ & & & HPLC/UV & & & \\
\hline Trehy et $\mathrm{al}^{7}$ & HPLC/DAD & & & & & \\
\hline Uchiyama et $\left.a\right|^{24}$ & & & HPLC/UV & & & \\
\hline Westenberger $^{9}$ & HPLC/UV, GC/MS & LC/MS/MS & & & & \\
\hline Westenberger $^{10}$ & HPLC/UV & LC/MS/MS & & & & \\
\hline Laugesen $^{22}$ & & LC/MS/MS & SIFTMS & ICP/MS & SIFTMS & SIFTMS \\
\hline
\end{tabular}


Table 9 Instrumental methods developed for PAHs, flavours, solvents, alkaloids, drugs and particles

\begin{tabular}{|c|c|c|c|c|c|c|}
\hline Literature & PAHs & Flavours & Solvents & Alkaloids & Drugs & Particles \\
\hline Etter et $a l^{13}$ & & & GC/FID, MS-EI & & & \\
\hline Schripp et $a l^{27}$ & & & & & & EMA \\
\hline Uryupin et $a \beta^{30}$ & & & ESI/MS, NMR & & & \\
\hline Williams et $a l^{26}$ & & & & & & SMPS-CPC \\
\hline Zhang et $a l^{31}$ & & & & & & SMPS \\
\hline Cheah et $a l^{17}$ & & & GC/FID, GC/MS & & & \\
\hline Ingebrethsen et $\left.a\right|^{29}$ & & & & & & ST \\
\hline McAuley et $a l^{11}$ & GC/MS & & GC/MS & & & WPS \\
\hline Pellegrino et $a l^{6}$ & & GC/MS & GC/MS & & & Aerocet \\
\hline Trehy et $a l^{7}$ & & & & $\mathrm{HPLC/DAD}$ & & \\
\hline Hadwiger et $a l^{18}$ & & & & & HPLC/DAD or MSMS & \\
\hline Westenberger $^{9}$ & & & NMR, GC/MS & HS GC/MS or MSMS & & \\
\hline Westenberger $^{10}$ & & & GC/MS & HPLC/UV, GC/MS & & \\
\hline Laugesen $^{22}$ & GC/MS & & SIFTMS & & & \\
\hline
\end{tabular}

complex sample matrix is not well resolved by LCMS unless additional sample clean-up is completed before analysis. Such differences are expected to contribute to variations in quantitative and qualitative results.

Another noteworthy concern is that many of the analytical methods used in these studies have not been validated. Method validation is generally an important part of good laboratory practice (GLP) and good manufacture practice (GMP). It ensures good science, consistent application of method and comparability of data. Therefore, it would be helpful to develop validated analytical test methods to measure chemicals of interest in e-cigarettes.

\section{Aerosol generation}

The sample preparation for analysis of smoke/aerosol involves generation of the smoke/aerosol. The factors influencing e-cigarette aerosol generation include human use topography, machine aerosol generation parameters and aerosol generation techniques. Human use topography is important in determining true levels of human exposure to constituents in e-cigarettes. Smoking machine parameters for laboratory studies are important in understanding the way that constituent yields delivered by a tobacco product can change over a range of different smoking conditions. Studies of aerosol generation characteristics reveal that, compared with conventional cigarettes, e-cigarettes require a higher airflow rate and longer puff durations to produce aerosols. Furthermore, pressure drop $\left(\mathrm{mm} \mathrm{H}_{2} \mathrm{O}\right.$ across e-cigarettes during each puff) varies greatly across cartridges in

Table 10 Machine-smoking parameters used by Trtchounian ${ }^{1}$ in a lab-built device

\begin{tabular}{lll}
\hline Smoking properties & e-cigarettes & Conventional cigarettes \\
\hline Pump speed & $250 \pm 0$ to $725 \pm 40 \mathrm{rpm}$ & $250 \pm 0 \mathrm{rpm}$ \\
Vacuum & $25 \pm 3$ to $153 \pm 12 \mathrm{~mm} \mathrm{H} \mathrm{O}$ & $30 \pm 3$ to $80 \pm 5 \mathrm{~mm} \mathrm{H} \mathrm{O}$ \\
Aerosol density & $0.1 \pm 0.1$ to $0.5 \pm 0.2$ & $0.2 \pm 0.1$ to $0.9 \pm 0.4$ \\
\hline
\end{tabular}

models across brands and within a brand. ${ }^{1} 4712{ }^{20}$ Hua et al determined electronic nicotine delivery systems (ENDS) require longer puff durations with large variation (1.9-8.3 s). ${ }^{32}$ Hua's result is consistent with Farsalinos' research, which reported puff durations of $4.2 \pm 0.7 \mathrm{~s} .{ }^{33}$ The results suggest that standard protocols used to test conventional cigarettes are not necessarily applicable to e-cigarettes. Table 10 presents a side-by-side comparison of e-cigarette and conventional cigarette smoking parameters ${ }^{1}$ that clearly indicates the remarkable difference between e-cigarettes and conventional cigarettes regarding the vacuum and pump speed applied for aerosol generation in a laboratorybuilt device. Table 11 summarises the parameters and instrumentation used for aerosol generation in the chemistry studies. The wide range in smoking parameters and instrumentation demonstrate the lack of standardisation in methodologies for aerosol generation used for e-cigarette analyses.

\section{Performance}

The performance of e-cigarettes depends fundamentally on the physical and electronic design of the device. Performance properties include airflow, pressure drop, aerosol density, puff strength (ie, vacuum required to produce aerosol) and number of puffs. Studies of e-cigarette devices have found that aerosol generation performance varies by brand and even by product within a specific brand. ${ }^{14}{ }^{12}$ Evidence of this is demonstrated by Trtchunian's 2010 study showing that the total puff number ranges from $30 \pm 43$ for one brand to $313 \pm 115$ for another brand. ${ }^{1}$ The relatively high SD $( \pm 43$ and \pm 115 , respectively) from each mean (30 and 313, respectively) indicates large performance variance by product within a specific brand. Furthermore, in 2011, Williams et al ${ }^{12}$ recorded aerosol density for every other puff during the first 10 puffs of four e-cigarette models. They observed dissimilarity in aerosol density among models and between two samples of one model. Therefore, variations observed in these properties appear to be associated with both e-cigarette design and e-cigarette product qualities, suggesting a need for improved quality control during manufacture. 
Table 11 Summary of reported e-cigarette machine (lab device) smoking parameters

\begin{tabular}{|c|c|c|c|c|c|c|c|c|}
\hline Literature & Puff volume (mL) & Puff interval (s) & Puff duration(s) & Puffs/session & Total puffs & Series & Series interval (min) & Smoking machine \\
\hline Goniewicz et al ${ }^{4}$ & 70 & 10 & 1.8 & 15 & 300 & 20 & 5 & Palaczbot* \\
\hline Goniewicz et $\left.a\right|^{20}$ & 70 & 10 & 1.8 & 15 & 150 & 10 & N.A. & Palaczbot* \\
\hline Pellegrino et $a l^{6}$ & 498 & 8 & 3 & 16 & N.A. & N.A. & N.A. & Aspiration \\
\hline Ingebrethsen ${ }^{29}$ & 55 & 30 & 2 to 4 & 10 & N.A. & N.A. & N.A. & Lab-built device \\
\hline McAuley et al ${ }^{11}$ & 50 & 30 & 4 & 50 & N.A. & N.A. & N.A. & SCSMt \\
\hline Trehy et $a l^{7}$ & 100 & 60 & 2 & 30 & N.A. & N.A. & N.A. & Lab-built device \\
\hline Williams and Talbot ${ }^{12}$ & N.A. & 60 & 2.2 & $10 / 11$ & N.A. & N.A. & N.A. & Lab-built device \\
\hline Cobb et $a l^{8}$ & 35 & 60 & 2 & $\geq 50$ & N.A. & N.A. & N.A. & Machine ISO \\
\hline Trtchounian et al ${ }^{1}$ & N.A. & 60 & 2.2 & 10 & 30 to 313 & 3 & 15 & Lab-built Puff box \\
\hline Uchiyama et $a^{24}$ & N.A. & N.A. & N.A. & N.A. & N.A. & N.A. & N.A. & Plemium Smoker \\
\hline Westenberger ${ }^{9}$ & 100 & 60 & N.A. & N.A. & N.A. & N.A. & N.A. & Lab-built device \\
\hline Laugesen $^{22}$ & 38,58 & N.A. & N.A. & N.A. & N.A. & N.A. & N.A. & Syringe \\
\hline
\end{tabular}

\section{Aerosol particle size distribution}

Pellegrino et al measured the ultrafine particulate matter (PM) fraction yield of e-cigarettes. Data showed that the PM emission values were lower in e-cigarettes compared with the conventional cigarette (eg, $\mathrm{PM}_{1}=14 \mathrm{vs} 80 \mu \mathrm{g} / \mathrm{m}^{3}$ and $\mathrm{PM}_{10}=52$ vs $922 \mu \mathrm{g} / \mathrm{m}^{3} ; \mathrm{PM}_{1}$ and $\mathrm{PM}_{10}$ are particulate matter emission with particle size lower than 1 or $10 \mu \mathrm{m}){ }^{6}$ Ingebrethsen et al discovered that aerosol dilution, which is necessary for detection of aerosol particle size when using an electrical mobility analyser, results in average particle diameters in the $50 \mathrm{~nm}$ range, compared with the $250-450 \mathrm{~nm}$ range determined by spectral transmission measurement, due partially to aerosol particle evaporation at the dilution levels. The authors suggested measuring e-cigarette aerosols in an undiluted state by using the spectral transmission method. ${ }^{29}$ A recent in vitro study by Zhang et al demonstrated that under the conditions of a single puff experiment, during which the aerosol does not reach steady state, an e-cigarette generates an aerosol having particle sizes in the range $100-600 \mathrm{~nm}$, which is similar to that of conventional cigarettes. ${ }^{31}$ The authors noted that the single puff experiment generates much smaller particles than would be expected if the aerosol approached steady state; they also suggested that future studies could assay aerosols generated by human users. In another recent study by Schripp et al, the investigators concluded that the inhaled "aerosol size distribution alters in the human lung and leads to an exhalation of smaller particles. The effect is caused by the evaporation of the liquid particles in the lung and also in the environment after exhalation." ${ }^{27}$ Varying results in particle size distributions of PM emissions from e-cigarettes across studies indicate that standardised and valid determination methods are necessary in order to evaluate the real exposure to users and the mechanisms (such as the evaporation of solvents and the agglomeration and deposition of particles) underlying such exposure.

\section{CONCLUSION}

As of September 2013, 29 published non-clinical studies evaluated the chemistry of e-cigarettes. Various chemical substances and ultrafine particles known to be toxic, carcinogenic and/or to cause respiratory and heart distress have been identified in e-cigarette aerosols, cartridges, refill liquids and environmental emissions. In addition to the uniqueness of the liquid compositions in each brand, inconsistency of both the device performance properties and the data collection methodologies used by researchers contribute to the observed variation in constituent levels and to the range of particle size distributions among products. Moreover, few of these methods are well validated. In addition, e-cigarette use behaviours have only been taken into account for aerosol generation in two publications. Therefore, additional studies based on scientifically validated aerosol generation methods, aerosol physical property measurement methods and chemical analysis methods would be helpful in generating reliable estimates of chemical quantities and, thus, the toxic potential of e-cigarettes.

\section{CRITICAL INFORMATION GAPS}

Overall, existing studies provide certain insights about e-cigarettes, but study limitations exist and critical information gaps remain. Limitations include a clear lack of uniformity in methods used to produce aerosols and to analyse target constituents in e-cigarettes. Furthermore, half of the studies identified (the most recent ones) evaluated e-cigarettes sold in foreign markets (eg, Poland, Korea, Italy, New Zealand, Japan), indicating a strong need for evaluation of products currently on the US market. Limited attention has been focused on e-cigarette device designs, design evolution (both manufacturer and userinitiated) and the corresponding alteration of chemical substance release patterns. Finally, the effects of carrier solvents and additives, including flavour ingredients, on aerosol generation, aerosol physical properties and the chemical profile of e-cigarette emissions have not been reported.

\section{OTHER RECOMMENDED RESEARCH ACTIVITIES}

Subsequent studies of e-cigarettes should be developed to evaluate human use factors, levels of human external and internal exposure, and health effects. Data collected from these studies will inform the science base needed to effectively evaluate and regulate e-cigarettes. 


\section{What this paper adds}

- This is a systematic and comprehensive review of published studies related to the chemistry of e-cigarettes.

- e-cigarette brands and models differ in nicotine yield efficacy and consistency, and nicotine delivery is not uniform between puffs, brands or within a brand; furthermore, actual nicotine levels may not match labelled amounts.

- Wide ranges in the levels of chemical substances such as tobacco-specific nitrosamines, aldehydes, metals, volatile organic compounds, phenolic compounds, polycyclic aromatic hydrocarbons, flavours, solvent carriers, tobacco alkaloids and drugs have been reported in e-cigarette refill solutions, cartridges, aerosols and environmental emissions.

- Ultrafine particulate matter with different particle size distribution ranges has been reported in e-cigarette aerosols and environmental emissions.

- Standards of e-cigarette aerosol generation and validation of chemical testing would be helpful in generating reliable estimates of chemical quantities and, therefore, the toxic potential of e-cigarettes.

Acknowledgements The author would like to thank Dr Matthew Holman, Dr Michael Koenig and Dr Thomas Eads for the discussions and reviews during the research process, and Mr. Paul Aguilar, Ms. Deborah Neveleff, Dr Elizabeth Durmowicz, Dr Carolyn Dresler, Dr Cathy Backinger, Dr Candice Jongsma and Dr Corinne Husten for their support in the preparation of this article.

Contributors TC conducted the literature search, reviewed abstracts and composed this paper. She is the guarantor.

\section{Competing interests None.}

Patient consent No.

Provenance and peer review Not commissioned; externally peer reviewed.

Open Access This is an Open Access article distributed in accordance with the Creative Commons Attribution Non Commercial (CC BY-NC 3.0) license, which permits others to distribute, remix, adapt, build upon this work non-commercially, and license their derivative works on different terms, provided the original work is properly cited and the use is non-commercial. See: http://creativecommons.org/ licenses/by-nc/3.0/

\section{REFERENCES}

1 Trtchounian A, Williams M, Talbot P. Conventional and electronic cigarettes (e-cigarettes) have different smoking characteristics. Nicotine Tob Res 2010;12:905-12.

2 Pauly J, Li Q, Barry MB. Tobacco-free electronic cigarettes and cigars deliver nicotine and generate concern. Tob Control 2007;16:357.

3 Henningfield JE, Zaatari GS. Electronic nicotine delivery systems: emerging science foundation for policy. Tob Control 2010;19:89-90.

4 Goniewicz ML, Kuma T, Gawron M, et al. Nicotine levels in electronic cigarettes. Nicotine Tob Res 2013:15:158-66.

5 Chen I. FDA summary of adverse events on electronic cigarettes. Nicotine Tob Res 2013;15:615-16.

6 Pellegrino RM, Tinghino B, Mangiaracina G, et al. Electronic cigarettes: an evaluation of exposure to chemicals and fine particulate matter (PM). Ann Ig 2012;24:279-88

7 Trehy ML, Ye W, Hadwiger ME, et al. Analysis of electronic cigarette cartridges, refill solutions, and smoke for nicotine and nicotine related impurities. J Liq Chromatogr Relat Technol 2011;34:1442-58.
8 Cobb NK, Byron MJ, Abrams DB, et al. Novel nicotine delivery systems and public health: the rise of the "e-cigarette". Am J Public Health 2010;100:2340-2.

9 Westenberger BJ. Evaluation of e-cigarettes. Washington, DC: U.S. Food and Drug Administration, 2009. http://www.fda.gov/downloads/drugs/scienceresearch/ ucm173250.pdf (accessed 25 Oct 2013).

10 Westerberger BJ. Evaluation of Johnson Creek Liquids for E-cigarette Fills. Washington, DC: U.S. Food and Drug Administration, 2009.

11 McAuley TR, Hopke PK, Zhao J, et al. Comparison of the effects of e-cigarette vapor and cigarette smoke on indoor air quality. Inhal Toxicol 2012;24:850-7.

12 Williams M, Talbot P. Variability among electronic cigarettes in the pressure drop, airflow rate, and aerosol production. Nicotine Tob Res 2011;13:1276-83.

13 Etter J, Zather E, Svensson S. Analysis of refill liquids for electronic cigarettes. Addiction 2013;108:1671-9.

14 Kubica P, Kot-Wasik A, Wasik A, et al. "Dilute \& shoot" approach for rapid determination of trace amounts of nicotine in zero-level e-liquids by reversed phase liquid chromatography and hydrophilic interactions liquid chromatography coupled with tandem mass spectrometry-electrospray ionization. J Chromatogr A 2013;1289:13-18

15 Cameron JM, Howell DN, White JR, et al. Variable and potentially fatal amounts of nicotine in e-cigarette nicotine solutions. Tob Control 2014;23:77-8

16 Kirschner R, Gerona R, Jacobitz K. Nicotine content of liquid for electronic cigarettes. Clin Toxicol 2013;51:684.

17 Cheah NP, Chong NW, Tan J, et al. Electronic nicotine delivery systems: regulatory and safety challenges: Singapore perspective. Tob Control 2014;23:119-25.

18 Hadwiger ME, Trehy ML, Ye W, et al. Identification of amino-tadalafil and rimonabant in electronic cigarette products using high pressure liquid chromatography with diode array and tandem mass spectrometric detection. $J$ Chromatogr A 2010;1217:7547-55.

19 Trtchounian A, Talbot P. Electronic nicotine delivery systems: is there a need for regulations? Tob Control 2010;20:47-52.

20 Goniewicz ML, Knysak J, Gawron M, et al. Levels of selected carcinogens and toxicants in vapour from electronic cigarettes. Tob Control 2014;23:133-9.

$21 \mathrm{Kim} \mathrm{HJ}$, Shin HS. Determination of tobacco-specific nitrosamines in replacement liquids of electronic cigarettes by liquid chromatography-tandem mass spectrometry. J Chromatogr A 2013;1291:48-55.

22 Laugesen M. Safety Report on the Ruyan E-cigarette Cartridge and Inhaled Aerosol. Christchurch: Health New Zealand Ltd., 2008. http://www.healthnz.co.nz/ RuyanCartridgeReport30-0ct-08.pdf (accessed 25 Oct 2013).

23 Ohta K, Uchiyama S, Inaba Y, et al. Determination of carbonyl compounds generated from the electronic cigarette using coupled silica cartridges impregnated with hydroquinone and 2,4-dinitrophenylhydrazine. Bunseki Kagaku 2011;60:791-7

24 Uchiyama S, Inaba Y, Kunugita N. Determination of acrolein and other carbonyls in cigarette smoke using coupled silica cartridges impregnated with hydroquinone and 2,4-dinitrophenylhydrazine. J Chromatogr A 2010;1217:4383-8.

$25 \mathrm{Lim} \mathrm{HH}$, Shin HS. Measurement of aldehydes in replacement liquids of electronic cigarettes by headspace gas chromatography-mass spectrometry. B Kor Chem Soc 2013;34:2691-6.

26 Williams M, Villarreal A, Bozhilov K, et al. Metal and silicate particles including nanoparticles are present in electronic cigarette cartomizer fluid and aerosol. PLOS One 2013;8:e57987.

27 Schripp T, Markewitz D, Uhde E, et al. Does e-cigarette consumption cause passive vaping? Indoor Air 2013;23:25-31.

28 Leondiadis L. Results of chemical analysis in nobacco electronic cigarette refills. Athens, Greece: Mass Spectrometry and Dioxin Analysis Laboratory, National Centre for Scientific Research "Demokritos", 2009.

29 Ingebrethsen BJ, Cole SK, Alderman SL. Electronic cigarette aerosol particle size distribution measurements. Inhal Toxicol 2012:24:976-84.

30 Uryupin $A B$, Peregudov AS, Kochetkov KA, et al. Qualitative and quantitative compositions of fluids for electronic cigarettes. Pharm Chem J 2013;46:687-92.

31 Zhang Y, Sumner W, Chen DR. In vitro particle size distributions in electronic and conventional cigarette aerosols suggest comparable deposition patterns. Nicotine Tob Res 2013:15:501-8.

32 Hua M, Yip H, Talbot P. Mining data on usage of electronic nicotine delivery systems (ENDS) from YouTube videos. Tob Control 2013:22:103-6.

33 Farsalinos KE, Romagna G, Tsiapras D, et al. Evaluation of electronic cigarette use (vaping) topography and estimation of liquid consumption: implications for research protocol standards definition and for public health authorities' regulation. Int $J$ Environ Res Public Health 2013;10:2500-14. 